\title{
La legionelosis como enfermedad profesional. Metodología de Valoración
}

\section{Legionella pneumonia as an occupational disease. Valuation Methodology}

\author{
Marta Dorronsoro Dorronsoro', José Manuel Vicente Pardo² \\ 1. Médico Evaluador en Unidad Médica Equipo Valoración Incapacidades Gipuzkoa. INSS. España \\ 2. Jefe Médico Unidad Médica Equipo Valoración Incapacidades Gipuzkoa. INSS. España \\ Recibido: 05-06-14 \\ Aceptado: 18-06-14

\section{Correspondencia} \\ Marta Dorronsoro Dorronsoro. José Manuel Vicente Pardo \\ Pescadores Gran Sol, s/n \\ San Sebastián 20011 , \\ Gipuzkoa. España. \\ Correo electrónico: marta.dorronsoro@seg-social.es, jose-manuel.vicente@seg-social.es
}

Resumen

La Legionella es una enfermedad bacteriana producida por la Legionella Pneumofila, patógeno oportunista que para causar una enfermedad debe estar presente en el lugar (reservorio), debe alcanzar un número suficiente para causar la infección (amplificación) y debe pasar al ambiente en estado infectivo (diseminación) los focos de contaminación que con mayor frecuencia han sido relacionados con los brotes epidémicos son instalaciones de suministro de agua y de acondicionamiento del aire de los edificios como: circuitos de distribución de agua caliente sanitaria, sistemas de climatización, aguas termales de centros de rehabilitación y recreo, equipos de aerosolterapia. El desarrollo de la enfermedad depende de la exposición al microorganismo patógeno, de la virulencia y de la inmunidad del huésped.

La enfermedad puede ser asumida como enfermedad profesional cuando su aparición va ligada a la exposición al agente patógeno, demostrada su presencia en el medio de trabajo y realizando tareas en las que es posible su infección. En este artículo a propósito de un caso se establecen los pasos para la determinación de la contingencia profesional de una enfermedad causada por exposición a agentes biológicos

Material y método: Se han revisado hasta mayo de 2013 las siguientes bases de datos bibliográficas: SciELO, y PUBMED. Así como la Bibliografía y documentos de consulta citados en la misma

Conclusiones: la neumonía por legionella puede contraerse tanto con carácter ocupacional ligado al trabajo como ambiental. Como toda enfermedad profesional, la diferencia no está en los signos o síntomas de la enfermedad, que no difieren en la neumonía por legionella ni en la clínica ni en la analítica, ni en las pruebas de imagen en cuanto al origen causal, sea este ambiental o de ocio o en la práctica laboral, sino que su adscripción diferencial causal ligada al trabajo viene definida por cumplir con los requisitos legales que dotan a esta enfermedad del carácter profesional en nuestro país. La enfermedad profesional es en materia de seguridad social un constructo legal, es decir una figura regulada por la norma, que define el concepto de enfermedad profesional que no es otra que la referida en el art. 116 del TRLGSS que define el concepto de enfermedad profesional y el RD 1299/2006 que establece el cuadro o lista de enfermedades profesionales, y es en la metodología adecuada de análisis de los supuestos donde hayamos la base para su clasificación correcta.

Med Segur Trab (Internet) 2014; 60 (235) 358-369

Palabras clave: Neumonía por legionella, enfermedad profesional, riesgo laboral. 


\section{Abstract}

Legionella is a bacterial disease caused by Legionella pneumophila, an opportunistic pathogen to cause a disease that must be present in the place (reservoir), must reach sufficient numbers to cause infection (amplification) and must pass the environment on infection status (spread) sources of pollution that are most often associated with outbreaks are water supply installations and air conditioning systems (HVAC) of buildings as distribution channels for domestic hot water, hot springs center rehabilitation and recreation equipment and aerosol. The development of the disease depends on pathogen exposure, virulence and host immunity.

The disease can be assumed as an occupational disease when their occurrence is linked to exposure to the pathogen, demonstrated its presence in the working environment and performing tasks that your infection is possible. This article about a case the steps for determining labor contingency of a disease caused by exposure to biological agents are set.

Methods: We reviewed until May 2013 the following bibliographic databases: SciELO, and PUBMED. As the bibliography and reference documents cited in the same

Conclusions: legionella pneumonia collapsible character both work-related occupational and environmental. Like any occupational disease, the difference is not in the signs or symptoms of the disease, which do not differ in legionella pneumonia or clinical or laboratory findings, or imaging tests as to the causal origin, be it environmental or entertainment or work practice, but their causal differential linked to the work assignment is defined by meeting legal requirements that give professional nature of this disease in our country. An occupational disease is social security a legal construct that is regulated by the standard is set, which defines the concept of occupational disease is none other than that referred to in art. TRLGSS 116 which defines occupational disease and the RD 1299/2006 establishing the list box or occupational disease, and the appropriate methodology for analyzing the cases where we have the basis for correct classification.

Med Segur Trab (Internet) 2014; 60 (235) 358-369

Keywords: pneumonia legionella, occupational disease, occupational hazard. 


\section{INTRODUCCIÓN SOBRE LA LEGIONELOSIS}

Se trata de una bacteria Gramm negativa. Patógeno oportunista que se transmite por vía aérea y que fue descubierta, tras haberse producido en Filadelfia en 1976 un brote epidémico en la convención anual de la Legión Americana. De los 4.000 asistentes, 221 contrajeron una neumonía como resultado de la exposición a un agente infeccioso no identificado. De los 221 enfermados murieron 34 personas.

En 1977 el CDC (Centro de control de enfermedades) descubrió este agente causal, al que atribuyeron otros brotes epidémicos similares ocurridos con anterioridad, pero cuyo origen infeccioso no era conocido.

En 1995 se crea en España la Red Nacional de Vigilancia Epidemiológica (RD 2210/1995, 28 de diciembre. BOE de 24 de enero de 1996), y a partir de su publicación, la legionelosis fue incluida como Enfermedad de Declaración Obligatoria (EDO) y fue reconocida como enfermedad profesional en el Real Decreto 1299/2006, de 10 de noviembre según el código 3D0105.

La Legionella puede producir dos tipos de enfermedades:

1. La enfermedad del Legionario, que se trata de una forma severa de neumonía. Tiene un periodo de incubación de 2-10 días, puede aparecer afectación de otros órganos como riñón, hígado, tracto gastrointestinal y sistema nervioso y una proporción de casos fatales del 15-20\%.

2. La Fiebre de Pontiac, cuyo periodo de incubación es de uno o dos días, una incidencia del 95\%, presenta una sintomatología gripal, puede haber pleuritis, pero no neumonía, no hay afectación de otros órganos y ausencia en general de casos fatales.

La Legionella es ubicua en medios acuáticos naturales como lagos, ríos o arroyos y así llega a los sistemas potabilizadores de agua, pudiendo ser transportada a los edificios donde puede colonizar las instalaciones de suministro de agua y los sistemas de acondicionamiento del aire.

Crece en agua a temperaturas comprendidas entre 20 y $50{ }^{\circ} \mathrm{C}$, con un desarrollo óptimo entre 35 y $45{ }^{\circ} \mathrm{C}$. Por debajo de $20{ }^{\circ} \mathrm{C}$ permanece latente, sin multiplicarse y no sobrevive por encima de los $60{ }^{\circ} \mathrm{C}$. Otros factores que tienen influencia en su desarrollo son el pH del agua (entre 2-9.5), la presencia de L-cisteína y sales de hierro y además se ha comprobado que algas y protozoos le otorgan un grado mayor de protección adicional frente a los tratamientos del agua.

Su supervivencia en el aire es corta ya que tiene poca resistencia a la desecación y a la radiación ultravioleta.

\section{EXPOSICIÓN A LEGIONELLA: RIESGOS PARA LA SALUD Y FOCOS DE CONTAMINACIÓN}

En general, existen dos tipos principales de organismos que pueden causar infecciones en el hombre: LOS PARÁSITOS OBLIGADOS como son los virus y algunas bacterias que precisan invadir células vivas para su crecimiento y reproducción y LOS SAPRÓFITOS FACULTATIVOS que pueden utilizar tanto materia orgánica muerta como células vivas. Dentro de estos saprófitos facultativos se encuentran patógenos primarios habitualmente encontrados en huéspedes vivos y patógenos oportunistas que se encuentran normalmente en el ambiente y sólo causan la enfermedad en circunstancias extraordinarias. 


\section{Riesgos para la salud}

Para que un microorganismo llegue a producir una enfermedad depende de dos factores: la virulencia y la inmunidad del huésped (un individuo sano es capaz de evitar casi todas las infecciones excepto las causadas por los patógenos más virulentos, mientras que los individuos con afectación de su sistema inmunitario pueden ser atacados con facilidad por patógenos oportunistas).

En el caso de la Legionella la principal vía de transmisión de la infección es la inhalación de aerosoles líquidos que contengan la bacteria. No ha sido documentada la transmisión entre personas ni la infección por la ingestión de agua contaminada.

Para causar la enfermedad la bacteria debe ser virulenta, estar presente en cantidades suficientes, ser dispersadas desde sus reservorios y alcanzar el fondo del pulmón. Una vez allí, la bacteria puede evadir las defensas del huésped parasitando las células fagocitarias.

La Legionella es un agente oportunista capaz de causar la enfermedad en personas especialmente susceptibles. Los factores de riesgo individual son los siguientes: edad avanzada (mayor de años), sexo masculino, tabaquismo (existe una relación muy importante entre el tabaquismo y el desarrollo clínico de la Neumonía por Legionella), individuos inmunodeprimidos o inmunocomprometidos, padecer diabetes o cáncer y pacientes con enfermedades respiratorias crónicas.

No obstante, los individuos sanos, también pueden padecer la enfermedad si han sufrido una exposición a concentraciones suficientemente elevadas.

\section{Focos de contaminación}

Para causar una enfermedad transmitida por vía aérea el microorganismo debe estar presente en el lugar (reservorio), debe alcanzar un número suficiente para causar la infección (amplificación) y debe pasar al ambiente en estado infectivo (diseminación).

Los reservorios, en el caso de los patógenos oportunistas son cualquier espacio que contenga suficientes nutriente y condiciones ambientales para mantener el desarrollo del microorganismo (depósitos de polvo, aguas estancadas y materiales humedecidos, por ejemplo).

La amplificación de estos microorganismos ocurre cuando las condiciones les resultan óptimas y permiten un rápido crecimiento (el aporte continuado de nutrientes como algas o protozoos, el rango óptimo de temperatura, humedad o $\mathrm{pH}$ ).

La diseminación, generalmente, requiere de alguna actividad que altere el substrato sobre el que se desarrolla: en algunos casos esta diseminación es propia del reservorio por ejemplo, el propio funcionamiento de la refrigeración y en otros casos resulta de la actividad humana al limpiar el reservorio.

En el caso de la Legionella los focos de contaminación que con mayor frecuencia han sido relacionados con los brotes epidémicos son las instalaciones de suministro de agua y de acondicionamiento del aire de los edificios en los que se dan las condiciones óptimas para el desarrollo del agente. Entre ellos: Circuitos de distribución de agua caliente sanitaria (grifos, cabezales de ducha, sifones y tramos ciegos), sistemas de climatización y torres de refrigeración, aguas termales de centros de rehabilitación y recreo, equipos médicos de aerosolterapia y fuentes decorativas.

En estos sistemas la supervivencia y multiplicación de la bacteria se relaciona, además de la existencia de una temperatura óptima para su desarrollo, con la presencia de lodos, materiales de corrosión y otros microorganismos como amebas, algas y otras bacterias que le sirven de substrato y además, le ofrecen cierta protección frente a los tratamientos habituales de desinfección, que habitualmente consisten en la elevación de la temperatura y el uso de desinfectantes químicos. 
En la siguiente figura se muestra la relación entre las temperaturas de diseño de los diferentes equipos, el estado de desarrollo de la bacteria y la probabilidad del riesgo de multiplicación y como se ve en el esquema, los focos de contaminación más probable son: las torres de refrigeración, los cabezales de las duchas y los Yacuzzi, dado que sus temperaturas habituales de trabajo coinciden con las de máxima multiplicación de la bacteria.

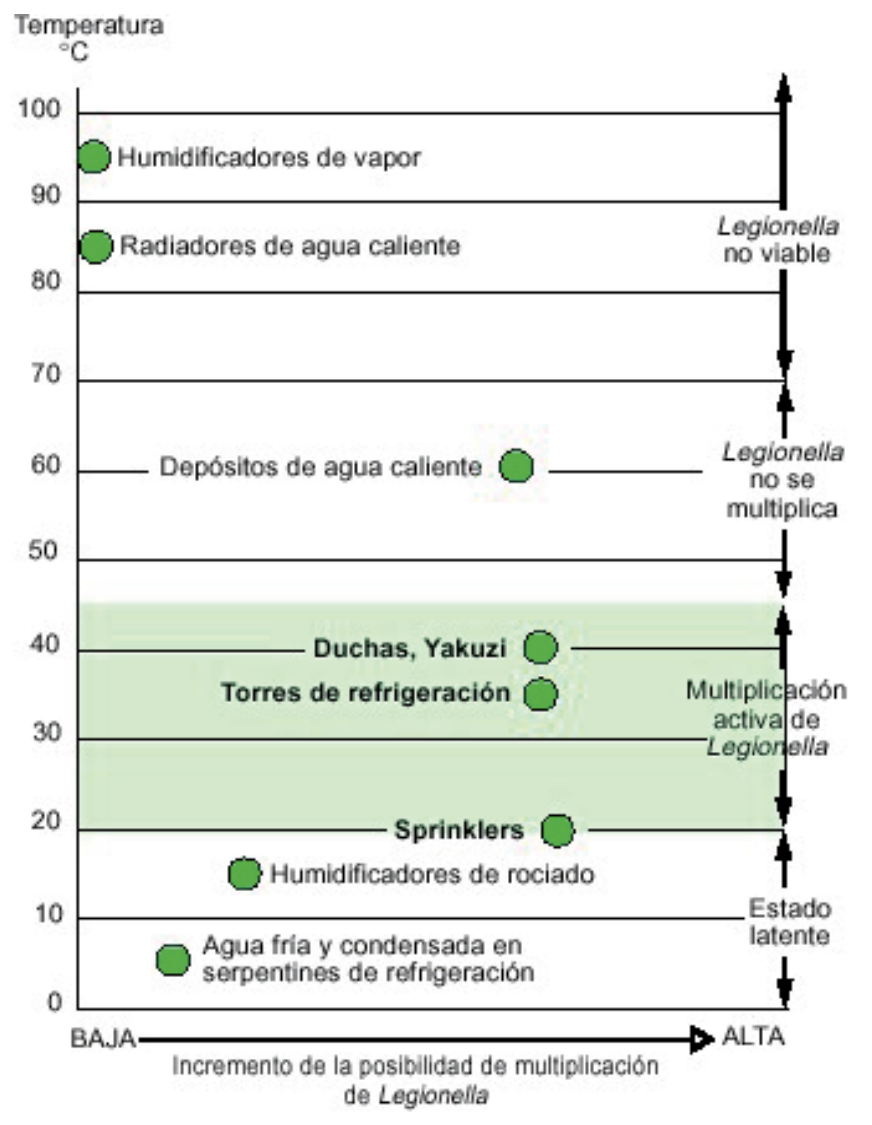

Ya que, como hemos dicho previamente, el mecanismo de transmisión de la Legionella es la vía aérea, para que la bacteria se disemine, es necesario que se genere un aerosol. Así, por lo que respecta a las instalaciones de suministro de agua, el aerosol se crea en los grifos y en los cabezales de la ducha.

En las instalaciones de acondicionamiento de aire los puntos más importantes son las torres de refrigeración y los humidificadores (aunque su papel en el origen de la enfermedad parece menos importante).

\begin{tabular}{llll}
\hline $\begin{array}{c}\text { LEGIONELLA } \\
\text { ufc/ml }\end{array}$ & \multicolumn{1}{c}{$\begin{array}{c}\text { TORRES DE } \\
\text { REFRIGERACIÓN }\end{array}$} & \multicolumn{1}{c}{$\begin{array}{c}\text { INSTALACIÓN DE } \\
\text { AGUA CALIENTE }\end{array}$} & \multicolumn{1}{c}{$\begin{array}{c}\text { HUMIDIFICADORES/ } \\
\text { NEBULIZADORES }\end{array}$} \\
\hline$<1$ & Bajo & Bajo & $\uparrow$ Bajo \\
\hline $1-9$ & Bajo & $\uparrow$ Bajo & Moderado \\
\hline $10-99$ & $\uparrow$ Bajo & Moderado & Alto \\
\hline $100-999$ & Moderado & Alto & Alto \\
\hline$>1000$ & Alto & Alto & Alto \\
\hline
\end{tabular}




\section{NORMATIVA MEDIDAS DE CONTROL Y PREVENCIÓN}

Como en cualquier otro ámbito de la prevención de riesgos laborales la posibilidad de contaminación por agentes biológicos debería ser tenida en cuenta en la fase de diseño de las instalaciones, en particular, las de climatización del aire y por supuesto, evitando el poner en riesgo a trabajadores especialmente susceptibles.

Es difícil disponer de métodos de prevención y control de Legionella totalmente eficaces, fundamentalmente por dos razones: por un lado, porque la Legionella es una bacteria ubicua en el ambiente en el que la erradicación sería prácticamente imposible y por otra parte porque es una bacteria más resistente que otros microorganismos a la acción de los medios físicos o químicos de control habitualmente empleados.

Diferentes autores han estudiado la eficacia in vitro de diferentes productos y métodos, como ozono, peróxido de hidrógeno comparando su eficacia con el cloro, otros han hecho estudios con el aumento de temperatura y la radiación ultravioleta y el uso de iones metálicos como cobre o plata, sin embargo, estos estudios realizados in vitro son poco extrapolables a las situaciones reales de diseño.

Por todo lo señalado anteriormente, el aspecto preventivo debe basarse en los Reales Decretos legislativos y normas UNE que tienen por objeto proporcionar criterios para la prevención de la contaminación de ciertas instalaciones y equipos por la bacteria Legionella y para el control de su multiplicación ambiental, entre los cuales destacamos:

- Informe UNE 100-030-94 sobre climatización: "Guía para la prevención del la Legionella en instalaciones.

- Real Decreto 1751/1988 de 31 de julio, por el que se aprueba el Reglamento de Instalaciones Térmicas en los edificios (RITE) y sus instrucciones técnicas complementarias (ITE) que establece las condiciones que deben cumplir las instalaciones térmicas de los edificios.

- Real Decreto 909/2001, de 27 de julio para la prevención de la Legionelosis.

- Real Decreto 865/2003, de 4 de julio, por el que se establecen los criterios higiénico-sanitarios para la prevención y control de la Legionelosis.

- Real Decreto 1218/2002, de 22 de noviembre por el que se modifica el RD 1751/1988.

- Real Decreto 664/1997 sobre la protección de los trabajadores contra los riesgos relacionados con la exposición a agentes biológicos.

En concreto, el Real Decreto 865/2003 tienen como objeto la prevención y control de la Legionelosis mediante la adopción de medidas higiénico-sanitarias en aquellas instalaciones en las que la legionella es capaz de proliferar y diseminarse y diferencia acciones preventivas tanto en el diseño y montaje de las instalaciones como en el mantenimiento y explotación y contempla en el artículo 9, la conexión con la ley de Prevención de Riesgos laborales (ley 31/1995 de 8 de noviembre) y con el Reglamento de los Servicios de Prevención, y en particular con el Real Decreto 664/1997 de 12 de mayo sobre la protección de los trabajadores contra los riesgos relacionados con la exposición a agentes biológicos.

Así mismo clasifica las instalaciones en función del riesgo como:

- Instalaciones de alto riesgo: torres de refrigeración y condensadores evaporativos. Sistemas de circuito de retorno. Sistemas de agua climatizada con agitación constante y recirculación a través de chorros de alta velocidad y centrales humidificadores industriales.

- Instalaciones de menor riesgo: sistemas de instalación interior de agua fría de consumo humano. Equipos de enfriamiento evaporativo que pulvericen agua. Humectadores. Fuentes ornamentales. Sistemas de riego por aspersión en el medio urbano. Sistemas de agua contra incendios. Elementos de refrigeración por aerosolización al aire libre. 
- Equipos de riesgo de terapia respiratoria.

- Quedan excluidas del ámbito de aplicación de este Real Decreto las instalaciones ubicadas en edificios dedicados al uso exclusivo de viviendas.

Con carácter general, las medidas preventivas irán encaminadas a impedir el desarrollo de la bacteria, modificando las condiciones de vida que le son favorables y a reducir la exposición minimizando la generación de aerosoles y por tanto, son dos los principios fundamentales en cuanto a medidas preventivas: uno, la eliminación o reducción de zonas sucias mediante un buen diseño y el mantenimiento de las instalaciones y otro, el control de la temperatura del agua y la desinfección continua de la misma.

\begin{tabular}{lll}
\hline \multicolumn{1}{c}{ TAREA } & \multicolumn{1}{c}{ FACTOR DE RIESGO } & \multicolumn{1}{c}{ PROTECCIÓN RESPIRATORIA } \\
\hline Revisión & Aerosol & $\begin{array}{l}\text { Mascarilla autofiltrante contra } \\
\text { partículas. }\end{array}$ \\
\hline $\begin{array}{l}\text { Limpieza y tratamiento químico } \\
\text { en espacio bien ventilado }\end{array}$ & $\begin{array}{l}\text { Aerosol y concentración baja de } \\
\text { cloro u otros agentes químicos }\end{array}$ & $\begin{array}{l}\text { Mascarilla con filtro antipartículas, } \\
\text { gases y vapores. }\end{array}$ \\
\hline $\begin{array}{l}\text { Limpieza y tratamiento químico } \\
\text { en espacio ventilado, sin }\end{array}$ & $\begin{array}{l}\text { Aerosol y concentración no muy } \\
\text { alta de cloro u otros agentes }\end{array}$ & $\begin{array}{l}\text { Mascarilla con filtro antipartículas, } \\
\text { gases y vapores. }\end{array}$ \\
\hline $\begin{array}{l}\text { Limpieza y tratamiento en } \\
\text { espacio confinado }\end{array}$ & $\begin{array}{l}\text { Auímicos } \\
\text { clorosol y concentración alta de }\end{array}$ & $\begin{array}{l}\text { Equipo de protección respiratoria } \\
\text { aislante autónomo con adaptador } \\
\text { facial tipo máscara completa }\end{array}$ \\
\hline
\end{tabular}

A nivel de protección individual debe utilizarse la mascarilla de protección biológica FFP3 en maniobras de elevado riesgo de exposición a Legionella.

Con carácter obligatorio, los titulares tanto de las instalaciones de mayor como de menor riesgo serán responsables de disponer de un registro de mantenimiento, en el que anotarán las operaciones de mantenimiento, reformas etc., así como control analítico de la calidad microbiológica físico-química del agua.

Hay que señalar que a nivel estatal hay cinco comunidades autónomas que se rigen por este Real Decreto 865/2003 como son Canarias, Ceuta y Melilla, La Rioja, Baleares, Murcia y País Vasco y el resto de las comunidades autónomas han creados sus propios Reales Decretos en los que basan la regulación jurídica de la prevención y control de la Legionelosis.

La responsabilidad derivada de estas infracciones puede determinar responsabilidades de tipo penal, administrativa, civil o en materia de Seguridad Social.

Y para finalizar, según el artículo 123 de la L.G.S.S. «todas las prestaciones económicas que tengan su causa en accidente de trabajo o enfermedad profesional se aumentarán según la gravedad de la falta, de un 30 a un 50 por 100, cuando la lesión se produzca por máquinas, artefactos en instalaciones, centros o lugares de trabajo que carezcan de los dispositivos de precaución reglamentarios, los tengan inutilizados o en malas condiciones, o cuando no se hayan observado las medidas generales o particulares de seguridad e higiene en el trabajo, o las elementales de salubridad o las de adecuación personal a cada trabajo, habida cuenta de sus características, de la edad, sexo y condiciones del trabajador».

\section{VALORACIÓN DE LA DETERMINACIÓN DE CONTINGENCIA}

A propósito de un caso de sospecha de enfermedad profesional, elevada desde el Servicio de Prevención, sobre Incapacidad Temporal de 22/11/2012 con diagnóstico de Neumonía bilobar por Legionella, en trabajador en centro termal de talasoterapia, con tareas polivalentes de mantenimiento con Alta Médica Laboral 18/01/2013, y cuestionándose si la baja lo es por Contingencia Común contingencia en la que permaneció de baja o por Contingencia Profesional como se postula.

El paciente fue citado a reconocimiento médico. 
Previo a la valoración definitiva del caso se estudiaron las referencias científicas a la enfermedad, la documentación aportada por la Mutua, y la solicitada al Servicio de Salud Laboral.

\section{Cronopatología}

Varón de 53 años que ingresó el 12/11/2012 en el hospital con un cuadro de disnea progresiva, tos persistente.

Como antecedentes personales, el trabajador era $\mathrm{HIV}+$, fumador de un paquete al día y VHC genotipo I. Como tratamiento habitual tomaba: Kivexa 1-0-0, Kaletra 4c/día y Omeprazol. En RX presentaba un infiltrado alveolar en LID y en segmento posterior del LSD. En la analítica, la antigenuria fue positiva para Legionella, con lo que se llegó al diagnóstico de Neumonía bilobar por Legionella. Fue tratado con Levofloxacino, Azitromicina, sueros y oxígeno, siendo la evolución satisfactoria y cursando alta hospitalaria el 26/11/2012.

\section{Actividad laboral}

El trabajador realizaba tareas como técnico polivalente de mantenimiento en un centro de Talasoterapia y $\mathrm{Spa}$, y ha venido realizando esta tarea en los últimos 6 años.

\section{Juicio diagnóstico}

Neumonía bilobar por Legionela, ya resuelta

\section{Circunstancias clínico-laborales}

Dado que se trata de una enfermedad de declaración obligatoria, el 14/12/2012 se comunicó desde la Unidad de epidemiología de la Subdirección Territorial de Salud Pública a la Unidad de Salud laboral (Osalan) y ante la tardanza en la declaración del caso por parte del Servicio de Prevención de la empresa, fue la propia unidad de Salud Laboral la que inició el trámite de declaración de sospecha de enfermedad profesional.

En el expediente de determinación de contingencia desde la Mutua, se aportó un informe médico poniendo de manifiesto los antecedentes personales del trabajador y mediciones de Legionella negativas realizadas en agua caliente sanitaria en la ducha exterior y en la entrada del circuito de la ducha de los chicos y en el agua de la piscina en el spa y en hidroterapia. Estas mediciones se realizaron durante el mes agosto de 2012. No se nos envió la descripción del puesto de trabajo ni la evaluación de riesgos.

Por ello le fue solicitada al Servicio de Salud Laboral, la descripción del puesto de trabajo y tareas, así como la evaluación de riesgos preceptiva sobre el mismo.

En el informe recibido del Servicio de Salud Laboral se contesta a estos extremos solicitados:

1. Descripción del puesto de trabajo: técnico de mantenimiento.

2. Descripción de las tareas del puesto: técnico polivalente en mantenimiento: realiza todo tipo de tareas de mantenimiento en las instalaciones. Se trata de instalaciones de termas, spas, centro de estética (con cabinas de hidromasaje), instalaciones deportivas (gimnasio) e instalaciones de restauración. En los días previos a la fecha de inicio de los síntomas (11/11/2012) realizó diferentes tareas de mantenimiento como reparación de grifos de cocina, de la cabina de hidromasaje 21 de las instalaciones y otros.

3. Toma de muestras de agua en diferentes puntos del circuito solicitadas por parte del Servicio de Salud Pública, siendo positiva a Legionella Pneumophila serogrupo 1 (150 UFC/L) en una muestra de retorno y siendo igualmente positiva a Legionella Pneumophila serogrupo 1 (100 UFC/L) en una muestra tomada en la cabina de hidromasaje 21 . 
4. Evaluación de Riesgos del puesto realizada por el área técnica del Servicio de Prevención en el que se identifica el riesgo de exposición a agentes biológicos Legionella.

\section{Criterios de causalidad}

- La Legionella es una enfermedad bacteriana producida por la Legionella Pneumofila, patógeno oportunista que para causar una enfermedad debe estar presente en el lugar (reservorio), debe alcanzar un número suficiente para causar la infección (amplificación) y debe pasar al ambiente en estado infectivo (diseminación).

- Habitualmente crece en agua a temperaturas comprendidas entre $20-50{ }^{\circ} \mathrm{C}$ con un desarrollo óptimo entre 35 y $45^{\circ} \mathrm{C}$.

- En el caso de la legionella los focos de contaminación que con mayor frecuencia han sido relacionados con los brotes epidémicos son instalaciones de suministro de agua y de acondicionamiento del aire de los edificios como: circuitos de distribución de agua caliente sanitaria, sistemas de climatización, aguas termales de centros de rehabilitación y recreo, equipos de aerosolterapia.

- Para que el microorganismo llegue a producir la enfermedad depende de dos factores: de la virulencia y de la inmunidad del huésped. Por ello, si bien es verdad que los individuos con sistema inmunitario indemne tienen menos posibilidades de contraer infecciones por patógenos oportunistas, también es verdad que expuestos a concentraciones suficientes del patógeno podrían desarrollar la enfermedad, y en el lado opuesto, aunque el trabajador padezca una enfermedad con alteración del sistema inmunitario tampoco desarrollaría la enfermedad sin exponerse al microorganismo patógeno.

- La Mutua en sus alegaciones nos remite a determinaciones de Legionela negativas, realizadas en julio/2012, cuando el trabajador contrajo la enfermedad en noviembre/2012 y el periodo de incubación de la legionela oscila entre 2-10 días (5-6 días lo más habitual), nunca de 4 meses, por lo que se solicitó al Instituto Vasco de Salud Laboral-Osalan documentación relativa a las tareas realizadas por el trabajador, a la evaluación de riesgos de su puesto de trabajo y a determinaciones realizadas en los días posteriores a la declaración de la enfermedad.

- Dicha documentación pone de manifiesto:

1. Que en la evaluación de riesgos está identificado el riesgo a exposición a agentes biológicos como legionela.

2. Que en los días previos a desarrollar la enfermedad realizó diversas tareas de mantenimiento como reparación de grifos de cocina y de cabina de hidromasaje $n^{\circ} 21$ de las instalaciones.

3. Que en mediciones realizadas el $03 / 12$ se obtuvieron determinaciones de 150 UFC/1 en agua caliente sanitaria y de 100 UFC/L en cabina 21 de hidromasaje. Según el INSHT las determinaciones entre 100-900 se valoran como: riesgo moderado en torres de refrigeración, riesgo alto en instalación de agua caliente y riesgo alto en humidificadores/nebulizadores.

- Además de todo esto la Legionela está incluida en el listado de Enfermedades Profesionales (Código 3D0105) para "trabajadores dedicados a la limpieza y mantenimiento de instalaciones que sean susceptibles de transmitir la legionela".

- Por lo tanto es claro y objetivo establecer el siguiente nexo de causalidad: entre el agente patógeno y la patología provocada o enfermedad desarrollada, identificación del riesgo, e inclusión en el listado de enfermedades profesionales.

\section{Metodología para su valoración como enfermedad profesional}

La enfermedad profesional es en materia de seguridad social un constructo legal, es decir una figura regulada por la norma, que establece el concepto de enfermedad 
profesional, normativa legal que no es otra que la referida en el art. 116 del TRLGSS que define el concepto de enfermedad profesional y el RD 1299/2006 que recoge el cuadro o lista de enfermedades profesionales, y es en la metodología adecuada de análisis de los supuestos donde hayamos la base para su clasificación correcta.

La definición legal de enfermedad profesional viene referida en el art. 116 TRLGSS, de la siguiente manera: Se entenderá por enfermedad profesional «la contraída a consecuencia del trabajo ejecutado por cuenta ajena en las actividades que se especifiquen en el cuadro que se apruebe por las disposiciones de aplicación y desarrollo de esta Ley, y que esté provocada por la acción de los elementos o sustancias que en dicho cuadro se indiquen para cada enfermedad profesional».

El anexo I del RD recoge el Cuadro de Enfermedades Profesionales

Para ser Enfermedad Profesional se precisa por tanto:

- Que la enfermedad haya sido contraída a consecuencia del trabajo. Que exista por tanto una relación probada de causalidad de la enfermedad con el trabajo.

- Que se trate de una enfermedad listada (anexo I)

- Enfermedad causada por exposición al agente contaminante

- Que se haya desarrollado un trabajo referenciado en el listado, como de riesgo (principales actividades capaces de producirlas)

- Que se haya estado expuesto a acciones, elementos o sustancias que en dicho cuadro se indican para cada enfermedad profesional. Demostrada presencia del agente causal

- Exposición constatada al agente

- Intensidad y duración

Pasos para la adscripción de una Enfermedad como Enfermedad Profesional

1. Averiguar la causa el origen de la enfermedad

2. Averiguar si tiene causa exclusiva en el trabajo que se realizaba

3. Averiguar vinculación necesaria con sustancias o elementos habitualmente manipulados en el puesto de trabajo

4. Averiguar la adscripción en el listado Anexo I de

a) Enfermedad,

b) Agente causal y

c) Trabajo con exposición a ese agente.

No cabe identificar la enfermedad profesional con la enfermedad contraída por razón del trabajo; el concepto de esta es mucho más restringido al precisarse, según lo dicho, que además de dicho requisito, tanto la enfermedad, como la causas que lo produce, sean algunas de las que figuran en el listado oficial de enfermedad profesional.

Nuestro sistema de clasificación de enfermedad profesional se basa en un sistema de lista cerrada, si bien la lista de las actividades es orientativa y enuncia las principales actividades causales. Dicho esto, cuando la enfermedad o la causa que lo producen no están incluidas en dicha lista oficial, y, pese a que pueda quedar acreditado que la misma viene ocasionada por la realización de un trabajo, su calificación no será la de enfermedad profesional y sí la de accidente de trabajo, de acuerdo con lo dispuesto en el artículo 115.2e LGGS que referencia las denominadas "enfermedades del trabajo" exigiendo eso si que tenga por causa exclusiva la realización del trabajo.

Sin olvidar que el RD 1299/2006 refleja la figura de la sospecha de enfermedad profesional, bien cuando desde el médico de atención primaria o del servicio público de salud se sospecha en el seguimiento de un paciente que este presenta una posible enfermedad profesional (comunicándolo a la Entidad Gestora a través de Unidad Salud Laboral o Inspección SPS) o bien cuando desde el Servicio de Prevención se sospecha en el seguimiento de un paciente que este presenta una posible enfermedad profesional. 
Pues bien y en cuanto al proceso que nos ocupa resulta:

El Grupo 3 es el correspondiente a las Enfermedades Profesionales causadas por Agentes Biológicos.

Como agente infeccioso y subagente o enfermedad causada se referencian las enfermedades infecciosas y parasitarias no contempladas en otros apartados como la micosis, la legionella y la helmintiasis (Agente D, subagente 01).

Y como principales actividades capaces de producirla la enfermedad cita a los trabajadores dedicados a la limpieza y mantenimiento de instalaciones que sean susceptibles de transmitir la legionella (Actividad 05).

\section{CONCLUSIONES}

Por lo tanto es claro y objetivo establecer el siguiente nexo de causalidad: entre el agente patógeno y la patología provocada o enfermedad desarrollada, la identificación del riesgo en el desarrollo de una actividad con inclusión en el listado de enfermedades profesionales.

Con todos estos datos, tras una revisión bibliográfica de la Legionella, así como de la legislación vigente y de las medidas de prevención y control en instalaciones de suministro de agua (INSHT), y las particulares circunstancias del caso presente, de la presentación de la enfermedad, su evolución y el desarrollo del trabajo del paciente, con valoración de los riesgos y del agente causal de su enfermedad, se resuelve el caso como Enfermedad Profesional según el Código 3D0105.

\section{BIBLIOGRAFÍA. Normativa al respecto y textos de referencia}

Real Decreto 1751/1988 de 31 de julio, por el que se aprueba el Reglamento de Instalaciones Térmicas en los edificios (RITE) y sus instrucciones técnicas complementarias (ITE) que establece las condiciones que deben cumplir las instalaciones térmicas de los edificios.

Real Decreto 909/2001, de 27 de julio para la prevención de la Legionelosis.

Real Decreto 865/2003, de 4 de julio, por el que se establecen los criterios higiénico-sanitarios para la prevención y control de la Legionelosis.

Real Decreto 1218/2002, de 22 de noviembre por el que se modifica el RD 1751/1988. Real Decreto 664/1997 sobre la protección de los trabajadores contra los riesgos relacionados con la exposición a agentes biológicos.

RD 1299/2006, 10 de noviembre, por el que se aprueba el cuadro de Enfermedades Profesionales en el sistema de la seguridad social y se establecen criterios para su notificación y registro (BOE $\mathrm{n}^{\circ} 302$ 19-12-2006).

Informe UNE 100-030-94 sobre climatización: «Guía para la prevención del la Legionella en instalaciones”.

Norma UNE 100030 IN/2005: Guía para la prevención y control de la proliferación y diseminación de la Legionella en las instalaciones. AENOR.

Norma ISO 11731-2/2004. Mayo de 2004 para la detección y enumeración de Legionella. AENOR

Orden SCO $/ 317 / 2003$, de 7 de febrero, que regula el procedimiento para la homologación de los cursos de formación del personal que realiza las operaciones de mantenimiento higiénico sanitario de las instalaciones objeto del RD 909/2001.

Guía para la prevención de la legionelosis en instalaciones de riesgo. Documentos de Sanidad ambiental de la Comunidad de Madrid. Abril 2006.

Ministerio de Sanidad y Consumo. Guías técnicas para la prevención de la legionelosis en instalaciones de riesgo: Sistemas de agua caliente Sanitaria. Agua fría de consumo Humano. Torres de refrigeración y condensadores evaporativos. Sistemas de agua climatizada con agitación constante y recirculación a través decoros de agua de alta velocidad o inyección de aire.

Revista de la sociedad española de Medicina y Seguridad del Trabajo (vol. 3 - ${ }^{\circ} 4$ - diciembre 2008).

Legionnaires disease. The control of legionella bacteria in water systems.Health \& Safety Commission. Ed. Crown. Nov. 2000. Great Britain.

NTP 538: Legionelosis: medidas de prevención y control en instalaciones de suministro de agua.

Hernández Calleja Ana. Legionelosis: Revisión de las normas reglamentarias (I). Aspectos generales. Barcelona: INSHT: NTP 691. 
Hernández Calleja Ana. Legionelosis: Revisión de las normas reglamentarias (II). Medidas específicas. Barcelona: INSHT: NTP 692.

Cortés Díaz José M. ${ }^{a}$ Técnicas de Prevención de Riesgos Laborales. Madrid. Ed. Tébar. $4^{a}$ Edición.

Manual para la prevención y control de la Legionelosis, aspergilosis y tuberculosis en instalaciones sanitarias. Junta de Andalucía.

Guía Técnica para la prevención y control de la Legionelosis. MSC.2006.

Guía de prevención y control de la Legionelosis en el ámbito laboral de la Junta de Andalucía. 2008.

Maladies des climatiseurs et des humidificateurs MOLINA, C. INSERM, Paris, 1986. 